\title{
How to Understand Baby Needs!
}

\author{
Karin Ritter* \\ Osteopath, Natural Health Professional and Physiotherapist, Dinkelsbuehl, Germany
}

Submission: November 13, 2017; Published: December 18, 2017

*Corresponding author: Karin Ritter, Turmgasse 16, D - 91550, Dinkelsbuehl, Germany, Email: praxis-karin-ritter@t-online.de

\section{Opinion}

The years that I worked with babies and toddlers gave me time to observe. This experience has shown me the following

Especially hick-ups in the abdomen of mother with an elevated thorax and a resulting high diaphragmatic tension causes problems for their children. These children cannot breathe in and out deeply. This results in hasty drinking, denial of being breast-fed, short screams that sound staccato and explosive bowel movement. Due to poor abdominal breathing, these babies and toddlers will later in life defecate only with problems - most of the times this malfunction can be seen already in the deferred excretion of the meconium of sometimes three to five days after birth. Fecal retention causes fermentation and results in flatulences. The children's permanent moaning causes the diaphragm to become harder and harder. The breathing becomes more heavily. The children overflex - umbilical and inguinal hernia are further consequences. The "having-tocarry-the-legs-while-lying-on-the-back phenomenon" makes abdominal breathing even harder, since the abdominal muscles are flexed. Many of these children will suffer from constipation when they go from milk to baby cereal. They will speak hastily, seem unsettled, have a high muscular tension and will not be able to perform under stress. They will also be more prone to illness and allergies.

The effect on these children, their families and our society are enormous. You can find further details in $\mathrm{m}$ second book, that will be published in December 2017.

One the one hand, parents take their children to my office during the first week after they were born and the time they learn how to walk. A lot of times the reason is that the parents notice something about their babies. They are different from others in the multiple ways. Some reasons are agitation, c-shaped recumbency, frequent crying, falling asleep fast while being held up and waking up every time they are put to bed again. Further reasons are crying, frequent posseting and awaking with a start. Also, the head is lopsided or flat due to their snorkeling breathing, high body tension or being able to put their head to one side only. It keeps spitting out the pacifier, it lies down in bed hyperextensively only, starts crying when being lied down on the belly and can only put its head down on the face and not on the side. More are flatulences, strabismus, rolling over on the same side only, deferred motoric coordination, one sided crawling or no crawling at all, getting up using the same leg over and over, walking with an inward bent leg. Furthermore, it is possible that it wants -or even has- to be carried around all the time. It cannot spend time on its own (Figure 1).

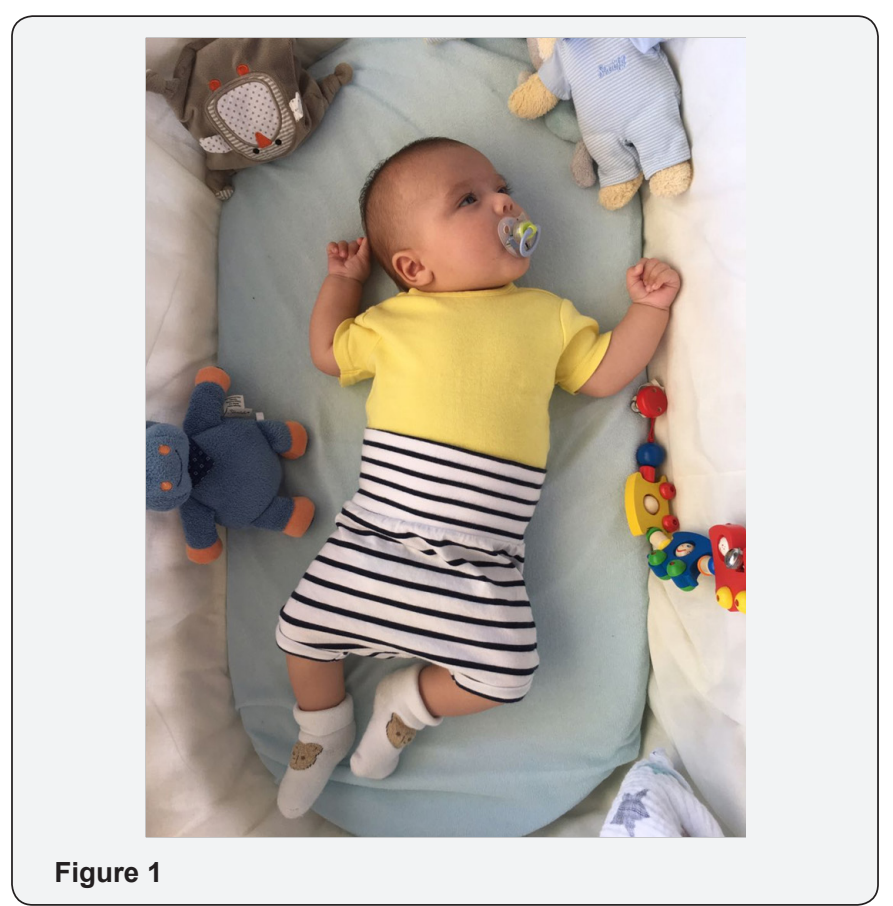

On the other hand, parents take their children to my office from age two to seven - especially because they notice them being different from their peers - siblings included. Here, the symptoms are usually hyperlordosis, bad posture, incontinence, UTI, constipation, internal rotation of the legs, recurrent angina, otitis media, headache, abdominal pain and sleeping troubles. Adding to these are behavioral disorder at home, at preschool, at school and when they are with friends. Furthermore, the parents 
notice unrest, a lacking concentration, poor fine-motor-skills, being sensitive to allergies and asthma.

The anamnesis of the older group of patients shows that they already had the above-mentioned symptoms of the first groups as a baby and that their parents had sought help for this matter before but had not found it.

Throughout the years that I have worked with babies and toddlers, I have noticed complications in both groups. Especially in terms of frequent hick-ups of the baby, that already started during pregnancy, pressure and tightness in the mother's abdomen. This pressure/tightness is usually caused by a lack of space or distress - distress of the mother but also distress that the baby is put under throughout the pregnancy, during birth or even after birth (thermically, chemically, mechanically or psychologically).

Having described the symptoms in the first part of the article, I will now go on with explaining my way to treat these symptoms. It is a new approach for the treatment of newborn and babies (Figure 2).

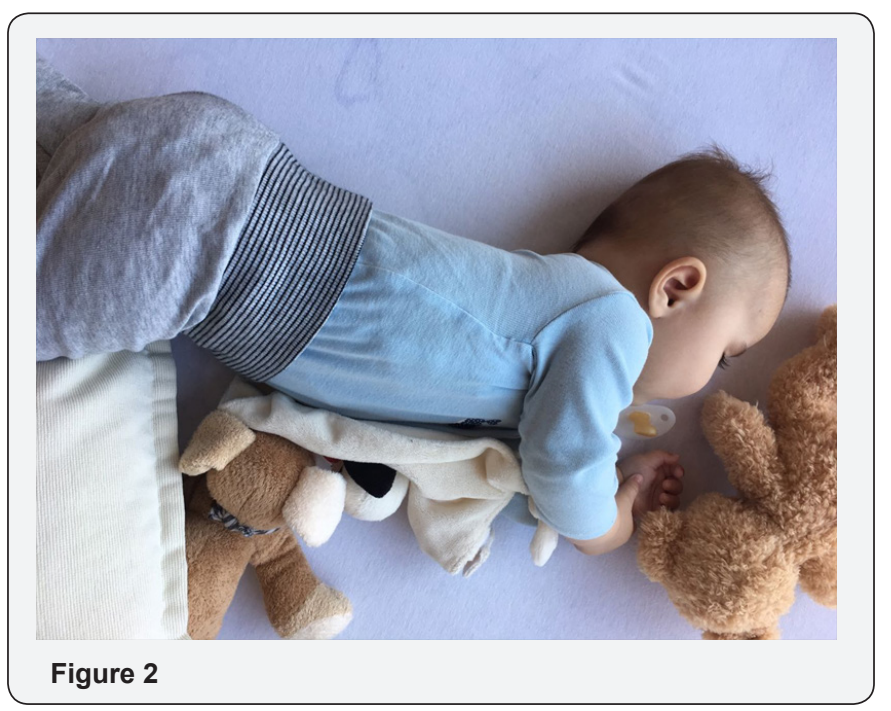

There are three essential things that unborn children do not acquire in the mother's womb. They do not learn how to stretch, they do not learn how to breathe and they do not learn how to defecate!

a) To learn how to stretch, the stretched abdominal position while being relaxed is the way to go.

b) To learn how to breathe, the whole thorax has to be caudal while breathing out.

c) And to learn how to defecate, three things are essential. One, the baby has to be able to perform abdominal breathing.

Two, the thorax has to come caudally. And three, the anus as to be dilative.

Here, physiology is being connected with neurology, with the reflexes of early childhood development, with the child's age and with the treatment of the caregivers. This means that the parents play an active part with the way they handle their child. They are advised to spot triggering the moto-reflex (e.g. not to lift their kids by grabbing them under the arms or not to lie them down/pick them up fast - in order to avoid a startle response-, not to grab them by the cervical vertebrae and not to carry them around while the child's head is hyperextended, etc.).

In addition, the children's automatic reflex patterns and posture-reactions can be supported by the parents -if necessary. It is necessary when the children, e.g., frequently startle up, fist, overflex, have a high body tension, scratch their face or tremble. Here, a so-called puck-scarf (a big piece of cloth that is wrapped around the child in a certain way) can be helpful, as well as keeping the child on their back with elevated legs.

Newborn babies simply are not able to perform the stretching of the hips -as a comparison, we cannot stretch our arm after it has been in a cast for six weeks either. So, they are only able to lie on their back in a relaxed and comfortable way when their legs are supported. This is why they are usually quiet when they are in a car seat or when they are being carried around. There, they usually also sleep and spit less -providing it is a proper car seat and the pillow under the back is removed. If this is not the case and the children cannot put their legs down while being on their back, they have to lift them up - this is what we call "kicking". We, too, would spit if we did Pilates to train our abdominal muscles after a big meal. And we, too, act like babies ourselves, if we are asked to lift our legs while lying down with a hollow back, overflexed head, looking up, mouth open (with relaxed jaws). And we, too, moan with exertion - and maybe even a little bit of air will pass from the mouth or the bowel.

And who can fall asleep in a flat position on the back? Nearly no one.

All parents that come to my office therefore bring a camera etc. with them and they record different improvements of their child after having changed and optimized their interaction with the child. So, they film the process of how they make their child achieve certain features. For example, to be symmetrically centered, to going to sleep, to rest, to drink properly, to lie down on the belly, on the back and on the side in a relaxed way, to move all their joints freely, to observe with focus and to play.

A first step that I take is to examine the child after the anamnesis and I take notes in case I notice something odd or special.

Then, I show the parents on a doll, what they should do with their child. Initially, the parents do everything themselves on their kid: they learn to look closely, to compare the flexibility of both sides and they learn the needed handling. I would like to say that in $90 \%$ of the cases, this "treatment" is already enough to achieve an enhancement of the general situation in every aspect. Only if there is no improvement after a couple of days, I treat the children in the proper sense of osteopathy. 
The parents have to learn to accompany the thorax caudally while breathing out and to hold it caudally while breathing in. After that, they have to learn to hinder their child's hyperflexion of the head. Because even if dural or other pulls, e.g. due to a $\mathrm{C}$-section, irritate the child and they are released in osteopathic treatment, the medical conditions or the unrest of the child can come back.

To emphasize this, I would like to present the following example. Newborn children underlie the moro-reflex. It causes, amongst other things, a head-extension which is so to say transmitted from the N. Vagus to the $\mathrm{N}$. accessorius. The result of both is as follows: shoulders up, jaws in compression, cervical vertebrae in extension, $\mathrm{C} 0 / 1 / 2$ in compression, the vegetative system in malfunction, intestine irritation, less stomach mobility and motility, faster breathing, diaphragmatic elevation, thorax in the breathing-in-position, higher muscle tone and the child is getting nervous more easily. Furthermore, the child is on higher alert for any sign of stress. This shows in eyes wide open, dilated pupils, wrinkly forehead, high blood pressure, release of adrenalin and cortisol - a vicious cycle is taking its course. A course that, if discussed, would go beyond the scope of this short presentation of my innovative treatment concept.

This form of treatment has a wide appeal. That is why I composed a manuscript in 2013 and forwarded it to TRIAS publishing house. Since June 2014, my book, "Understanding babies' needs", has been in stores and has been a fast selling item: Those who have it recommend it or distribute it to their friends and families. The second edition has been finished for hitting the market soon.

This article is short of many aspects of my treatment. However, you can read more about it and in more detail in my books. Additionally, films and visual material contribute to the understanding.

It is unbelievable how babies relax, become satisfied and quiet -on a permanent basis- and not rarely without my direct help as a osteopath. Of course, the atmosphere in the family positively changes and reciprocal understanding and trust develop. 